\title{
CURRICULUM RENEWAL FOR BETTER DESIGN-RELATED STUDENT OUTCOMES IN SECOND-YEAR CHEMICAL AND BIOLOGICAL ENGINEERING
}

\author{
Gabriel Potvin and Jonathan Verrett \\ Department of Chemical and Biological Engineering, University of British Columbia \\ gabriel.potvin@ubc.ca, jonathan.verrett@ubc.ca
}

\begin{abstract}
The Department of Chemical and Biological Engineering at UBC is currently undergoing a major curriculum renewal with the aim of modernizing the two undergraduate programs it offers to better prepare students for increasingly diverse industries. Part of this initiative aims to introduce design earlier and integrate it throughout the programs.

At the core of the new 2nd year curriculum are two new cornerstone courses: CHBE 220 and 221 - Fundamentals of Chemical and Biological Engineering I/II. CHBE 220 is taken in term 1 and replaces a previous classicallystructured physical chemistry course and an introductory seminar on process technology. It focuses on basic chemical process design and analysis, drawing from thermodynamics and kinetics as needed to support design topics. CHBE 221, offered in term 2, replaces a previous introductory cell biology course, and focuses on industrial microbiology and bioprocess design, drawing from cell and molecular biology and physical chemistry as needed to support design tasks. Both courses include substantial term-spanning design projects.

This paper outlines the content and structure of both courses and their place in the updated curriculum. It describes the integrated design projects and other course deliverables. Recommendations for future iterations of the courses are also presented.
\end{abstract}

Keywords: Design Education, Process Engineering, Bioprocess Engineering, Project-based Learning, Curriculum Renewal

\section{INTRODUCTION}

Over the past 25 years, many engineering programs have increased and distributed engineering design activities within their curricula [1]-[3] beyond the focused design experience provided by capstone courses. The deliberate integration of design activities throughout a curriculum is supported by literature as design draws on and consolidates many skills learned within undergraduate engineering programs [4]. Distributed practice studies also indicate that regularly spaced practice is more effective than massed practice (one large experience) in ensuring long-term skill development and mastery [5].

The Department of Chemical and Biological Engineering (CHBE) at the University of British Columbia (UBC) has been undergoing an intensive review of the two undergraduate programs it offers (Chemical Engineering and Chemical and Biological Engineering). This review is informed by consultations with faculty, students and industry representatives. Faculty members were consulted through graduate attribute data collection and department meetings. Students were consulted through focus groups held twice a term during which students from each year discuss individual courses, as well as through an annual survey on graduate attributes. Industry was engaged through an advisory council, which meets five times per year to discuss issues around education and research in CHBE. These consultation activities are ongoing in the department, forming the backbone of a continual improvement process.

These consultations identified a need to increase design instruction in the second and third year of our undergraduate programs. The goal of these increased design experiences was to introduce design earlier in the curriculum, enhance student design skills, and better prepare students for their capstone design experience. Because students enter CHBE (or any other engineering discipline) in $2^{\text {nd }}$ year, the first year being common for all engineering students at UBC, this integration also allows for a more comprehensive introduction to the chemical and biological engineering discipline and the particular design considerations and practices associated with it. The new $2^{\text {nd }}$-year curriculum was deployed for the 2019-2020 school year (denoted as 2019W).

At the core of the new $2^{\text {nd }}$ year curriculum are two new cornerstone courses: CHBE 220 - Fundamentals of Chemical and Biological Engineering I, and CHBE 221 Fundamentals of Chemical and Biological Engineering II. CHBE 220 is taken in term 1. It replaces a previous classically-structured physical chemistry course and an introductory seminar on process technology. It focuses on 
basic process design and analysis, drawing from thermodynamics and kinetics as needed to support design topics. CHBE 221, offered in term 2, replaces the previous introductory cell biology course. It focuses on industrial microbiology and bioprocess design, drawing from topics in cell and molecular biology and physical chemistry as needed to support design activities. Both courses are centered around term-spanning design projects that require students to integrate content being taught in class in selfcontained design activities surrounding a given chemical or biological process. Design activity deliverables are then combined into a final cohesive report at the end of the term.

This paper outlines the content of both courses and describes their integrated design projects and other deliverables. Recommendations for future iterations of the course, based on student feedback and performance and instructor experiences are also presented.

\section{COURSE DESCRIPTIONS}

\subsection{CHBE 220}

CHBE 220 replaces a three-credit physical chemistry course taught by the Faculty of Science at UBC (CHEM 251) and a one-credit seminar introducing chemical and biological engineering industries and process technologies (CHBE 243). Students reported that CHEM 251 was well taught, but had trouble seeing the connection between the natural science content of the course and engineering applications or design activities. CHBE 243 had a variety of guest speakers from a range of industrial areas. Though students found this interesting, they reported that they wanted to have a more overarching structure to the course and see how diverse topics were integrated into the chemical engineering discipline. The aim of CHBE 220 was to bridge natural science, engineering science and engineering design while introducing students to an array of different chemical process industries. The introduction of CHBE 220 also decreased the number of courses students were taking in the term from 8 to 7 , which had the support of all stakeholders. The change also shifted Accreditation Units (AUs) within the programs from

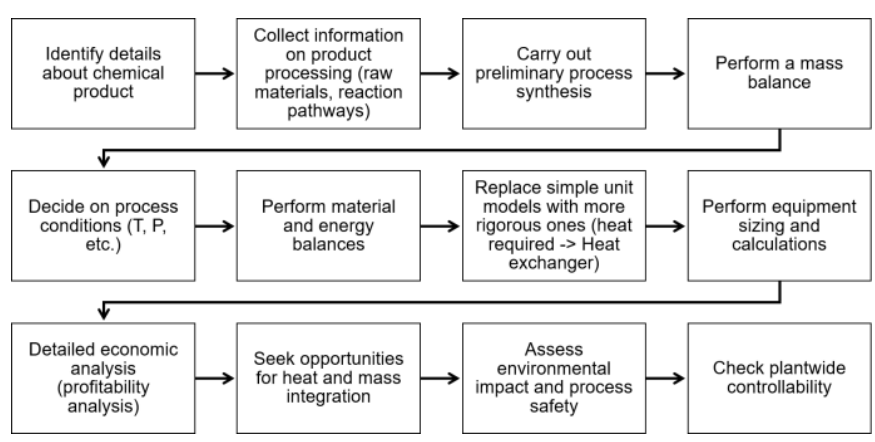

Fig. 1. Overarching CHBE 220 course framework, based on the chemical engineering design process. natural science to engineering design which put them in a more robust position in terms of continuing to meet $\mathrm{AU}$ requirements for accreditation.

It is worth noting that CHBE students had only technical communications (CHBE 201), a lab course (CHBE 262) and CHBE 243 as core courses (taken only by CHBE students) before curriculum changes were implemented. This was seen as a challenge in shaping disciplinary identity. The creation of CHBE 220 aimed to give students a better sense of chemical engineering, while also playing an important role in creating a disciplinary community. Integration between CHBE 220 and CHBE 201 was also implemented to further contextualize communication training. This had also been done previously with a material and energy balances course (CHBE 241), however CHBE 241 is taken by students from multiple engineering disciplines, making integration more difficult. This integration is further discussed in section 2.1.2.

\subsubsection{Content and Learning Objectives}

The course used the structure of a simplified chemical engineering design process drawn from literature [6], [7]. The overarching course framework, which was presented to students at least weekly in the course lectures is shown in Fig. 1. Lecture topics were chosen in order to give students the skills to perform analyses required for each part of the framework, and descriptions of lecture topics are listed below.

\section{i. Introduction to Chemical Processes and Diagrams}

- input-output diagrams, block flow diagrams, process flow diagrams, piping and instrumentation diagrams, basic unit operations

\section{ii. Chemical Reactions}

- reactor types, reaction rates and equilibrium, Arrhenius equation, reaction mechanisms

\section{iii. Phase Equilibrium}

- separation processes, gas properties, phase transitions, vapour-liquid equilibrium

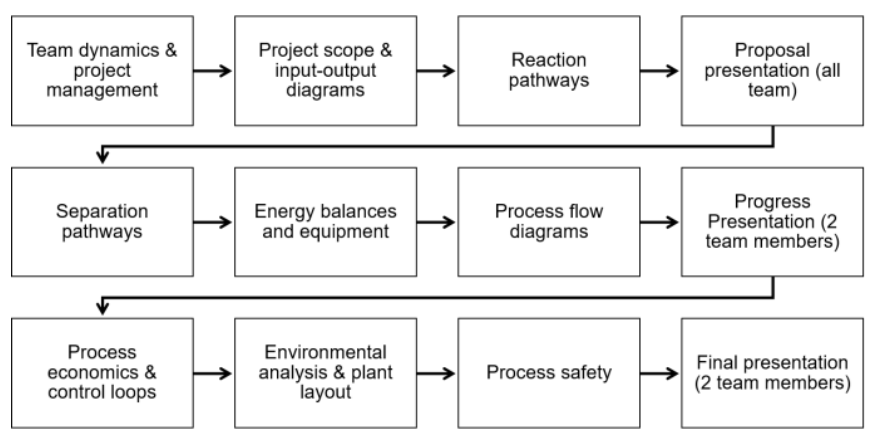

Fig. 2. CHBE 220 tutorial topics and progression throughout the term. 


\section{iv. Energy Balances}

- heat exchangers, thermodynamic data tables, heat capacity, phase changes, utility usage, reactive energy balances

\section{iv. Process Control}

- unsteady state material balances, common process control loops

\section{vi. Process Economics}

- capital cost estimation, operating cost estimation

\section{vii. Green engineering}

- fate of pollutants, life-cycle analysis interpretation

\section{viii. Process Safety}

- terminology, inherently safer design, hazard analysis techniques, what-if analysis, fault tree analysis interpretation

The course framework also drew from courses students were taking in the same term, such as Material and Energy Balances. Students were explicitly made aware of cases where they should draw from content from other courses. Certain topics were also presented as introductory, where further study would be done later in the program, and this was made explicit in the course. One example of this was plantwide controllability, where students were told they would take a process control course in their $3^{\text {rd }}$ year of study to build on the introductory knowledge presented in CHBE 220.

\subsubsection{Deliverables and Design Project}

The course consisted of three hours of lecture $(2 \times 1.5$ hours) and two hours of tutorial ( $1 \times 2$ hours) per week. Lecture time was used to introduce the topics outlined above. Active learning techniques such as clickers and think-pair-share were integrated into lectures. These were supplemented with individual exercises and problem sets due roughly every two weeks. Exercises were hosted on the WebWorK online homework platform and were computergraded. Problem sets consisted of more open-ended questions and generally asked students to find relevant data (without providing a specific source) for solving a design related problem. These were then graded by teaching assistants (TAs). The course also had one midterm and a final exam.

Tutorial time was used for students to meet with their design groups. Students ranked their preferences in working on five design topics and groups were assigned randomly based on topic preference. Design problems revolved around creating a certain amount of a given product at a given location. These problem statements were open-ended and a sample of one problem statement is give below.
"Your plant is seeking to produce ammonia and is located in southern Manitoba. Your job is to design a process and plant to produce 350,000 tonnes/yr of ammonia."

Topics were selected such that there would be a variety of well-known and viable process synthesis options and a variety of industrial areas. The five project options given to students were ammonia production, hydrogen production, diesel desulphurization, acetaldehyde production and carbon capture and storage. Tutorials focused on different topics in the chemical design process, a list of these topics is shown in in Fig. 2. Drawing from team-based learning strategies [8], students were asked to pre-read a 1 to 3 page introduction to a topic (typically an excerpt from a textbook) and complete a five-question multiple-choice individual quiz to assess readiness. Tutorial sessions were then themed to have students apply what they had learned in class and in the readings to their design project. TAs and the instructor were present to answer questions.

Deliverables were coordinated with CHBE 201 (technical communications) in order to help guide students in communicating their designs. Each tutorial had a deliverable, either a written submission roughly 1 page in length or a presentation. Students would receive feedback and a mark on the technical aspects of this deliverable from the CHBE 220 instructor. Three of these weekly submissions would also be put together for submission to CHBE 201 in order for students to receive feedback and evaluation on the technical writing components. Student presentations were done in tutorial sessions with CHBE 201 instructors present and giving feedback. At the end of the term a final deliverable consisting of compiled and revised weekly deliverables was submitted for a final project assessment. Student team contributions were assessed through peer evaluations after each presentation as well as an overall project peer evaluation. These peer evaluation scores were used in scaling team project marks to create individual project marks.

\subsection{CHBE 221}

CHBE 221 follows a similar structure to CHBE 220, and replaces a three-credit introductory cell biology course taught by the Faculty of Science (BIOL 112). Although the course was well taught, it was generally not very well appreciated by students who reported that it focused solely on natural science concepts, required memorization of details seen as irrelevant for engineers, and did not establish links to other courses in the CHBE curriculum or to relevant engineering applications. CHBE 221 introduces bioprocessing as a core structure around which elements of cellular and molecular biology are introduced to support students' work on designing a bioprocess to produce a bioproduct of their choice. 


\subsubsection{Context}

CHBE 221 is taken by all $2^{\text {nd }}$-year undergraduate students in both undergraduate programs (105 in the first cohort). Two distinct contextual challenges exist in offering this course.

The first is of a pedagogical nature and arises from the wide range of biology-related technical background of the students taking the course. At the beginning of the term, polling indicated that approximately half of the class had taken grade 12 biology (presumably within 2 years of taking CHBE 221) while as the other half had not covered biology content since the basic modules in grades 9 or 10 . A handful of students also had university-level biology courses taken either as technical electives, or as students in the Faculty of Science before transferring to Applied Science and CHBE. This presented a particular challenge in selecting material of suitable complexity or structuring the course in such a way as to be valuable for all students involved.

The second challenge was related more to disciplinary or academic culture. Because CHBE offers two distinct programs (Chemical Engineering and Chemical and Biological Engineering), and that students are admitted directly to their program of choice at the beginning of their studies in CHBE, students have already classified themselves as "bio" (approximately 40\%) and "not bio" (the remaining 60\%) students based on their interests. Since all CHBE students have to take this course, regardless of which program they are enrolled in, there was some skepticism and frustration by the "not bio" students about the need to take this course. This lack of buy-in not only complicates interaction and participation in the classroom but may cause difficulties in the group work on the extensive design project at the core of the course.

The first challenge was addressed by leveraging the open-endedness of the design project and a focus on content relevant to, and integrated with, engineering design. The latter challenge was mitigated by investing significant time in outlining value propositions for all engineers, breaking down conceptual barriers separating biology from other disciplines (relying instead on a continuum of chemistry with which students were more familiar), and regularly relating content to the designs the students were working on or to other industrial applications.

\subsubsection{Content and Learning Objectives}

The course was divided into modules covering the different stages of a cell-based bioprocess. As students progressed through the course content, they worked on related sections of the design project (outlined in section 2.2.3). The course used a framework of a simplified

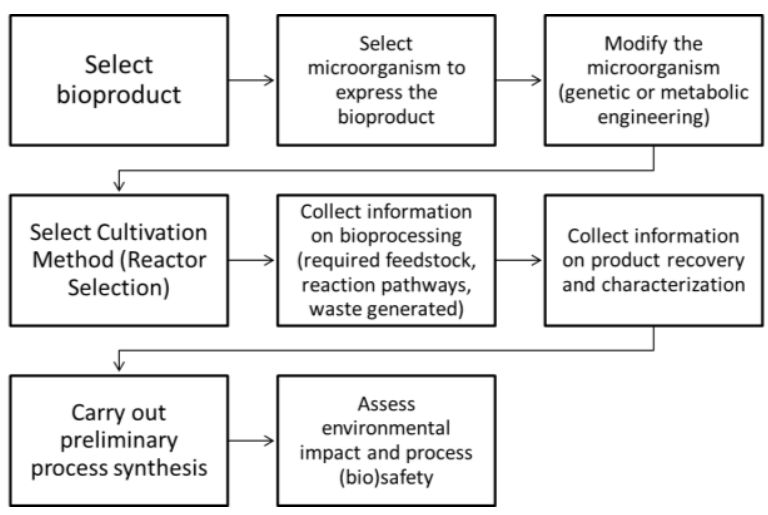

Fig. 3. Overarching CHBE 221 course framework, based on a condensed basic bioprocess design process.

bioprocess, modified from the model used in CHBE 220 and streamlined to mirror project deliverables. It is shown in Fig. 3.

The course focused on high-level learning outcomes related to the understanding of natural science concepts from each module, and their application in the design of bioprocesses to inform and justify engineering decisions.

Course modules consisted of:

\section{i. Bioprocess Core}

- Cell Biology (biodiversity, cell components, macromolecules, metabolism, bioproducts, enzymes)

- Cell Culture (Effect of operating conditions, growth media, Monod growth kinetics, bioreactor design, bioprocess control)

\section{ii. 'Upstream' Bioprocessing}

- Biological Information Flow (Central dogma of biochemistry, transcription and translation, gene regulation, protein engineering, expression cassette design, and genetic engineering)

- Metabolic Engineering (Metabolic flux mapping, introduction to metabolism modifications)

\section{iii. 'Downstream' Bioprocessing}

- Bioproduct Separation Processes (Cell lysis, adsorption, filtration, centrifugation, extraction, precipitation, crystallization, chromatography, drying, and associated design considerations)

- Quality Control (Introduction to QC, enzyme kinetics, product characterization) 


\subsubsection{Deliverables and Design Project}

Course deliverables consisted of traditional problembased assignments, a midterm, a final exam, and a termspanning design project.

The project was assigned during the first week of class and required students to select and conceptualize a process for the production of a bioproduct of interest. Students had free reign to choose the target product and built on their design experience in CHBE 220 with open-ended projects. The project was divided into four sections related to an aspect of the bioprocess being designed, aligned with relevant content covered in class. Project assessment followed an iterative submission pedagogy. Teams of 2-4 students submitted each of the sections individually (each worth $15 \%$ of the project grade), received detailed feedback on each section, and then resubmitted all sections as a cohesive final report (worth the remaining $40 \%$ of the project grade) at the end of the term, integrating the comments received on the earlier submissions. The four project sections were:

1 - Bioproduct and Cell Type Selection: Teams selected and described the bioproduct they wanted to produce, and the cell type they would use to produce it. Choices were justified in terms of technical feasibility, market analysis, and engineering considerations.

2 - Cell Culture and Bioreactor Design: Based on their decisions made in part 1 , teams selected and justified a reactor type, and selected operating conditions, growth media composition, and control strategies for the process, again based on technical feasibility and economic and engineering considerations.

3 - Gene Design and/or Metabolic Engineering: Teams described and justified a design for an expression cassette for their product (if a protein), or strategies for metabolic engineering (if a metabolite or novel metabolic pathway), all in the context of producing or maximizing bioproduct yields for the conditions outlined in part 2 of the project.

4 - Process Block Flow Diagram: Teams outlined and justified their selection of the unit operations of the overall process, with particular emphasis on separation and purification steps to achieve the target product with desired specifications.

Given the wide range of topics of interest, some deviations from the standard project format were allowed. The final report combined all four sections into a cohesive whole, which serves as an excellent showcase of course material and design skills of the students at this stage of their studies. The project as an assignment was presented to students in the context of self-directed specialized knowledge and skill development in an area of interest, built on the foundation of the basic concepts covered in class, and related to lifelong learning skills.

\section{STUDENT PERFORMANCE AND RECEPTION}

\subsection{CHBE 220}

Student evaluations of the course were completed by 66 out of 115 students (57\%). Students rated a variety of items on a five-point Likert scale from strongly disagree to strongly agree. Results from questions related to the overall course are shown in Table 1. Students found the course reasonably challenging but saw the material as relevant to their professional needs.

Table 1: CHBE 220 Student course evaluation responses.

\begin{tabular}{|l|c|c|c|c|c|}
\hline Question & SD & D & N & A & SA \\
\hline $\begin{array}{l}\text { The assigned workload for } \\
\text { the course was heavy }\end{array}$ & 3 & 12 & 28 & 16 & 7 \\
\hline $\begin{array}{l}\text { The course material is rather } \\
\text { advanced }\end{array}$ & 1 & 13 & 24 & 22 & 6 \\
\hline $\begin{array}{l}\text { The material is relevant for } \\
\text { my professional needs }\end{array}$ & 0 & 0 & 6 & 15 & 44 \\
\hline $\begin{array}{l}\text { The course material is } \\
\text { interesting }\end{array}$ & 0 & 1 & 14 & 26 & 24 \\
\hline
\end{tabular}

Comments from students at departmental focus group sessions and the student evaluations of teaching indicated they appreciated seeing the applications of natural and engineering science in the course through the design project. Students indicated there was some confusion about design project deliverables between CHBE 220 and CHBE 201 in terms of what should be submitted and expected formats. Students indicated that this improved as the term went on, but further improvements could be made to ensure expectations are clear. Future iterations of the course will focus on better integration and alignment of deliverables between courses.

A variety of textbooks were recommended for the course because it draws from a number of areas (physical chemistry, chemical engineering design, process safety, etc.). In order to make it easier for students to access course materials, open educational resources are being adapted or created to build a course textbook for students. This will seek to also offer students more examples and sample problems, as students commented on wanting more study resources. The course will continue to draw on a variety of library resources available at UBC, which was done in the current course iteration. Students also commented on a relatively significant overlap in certain content with the Material and Energy Balances course the same term. Though there is indeed overlap, the importance of this topic to the discipline is such that it is likely required. 


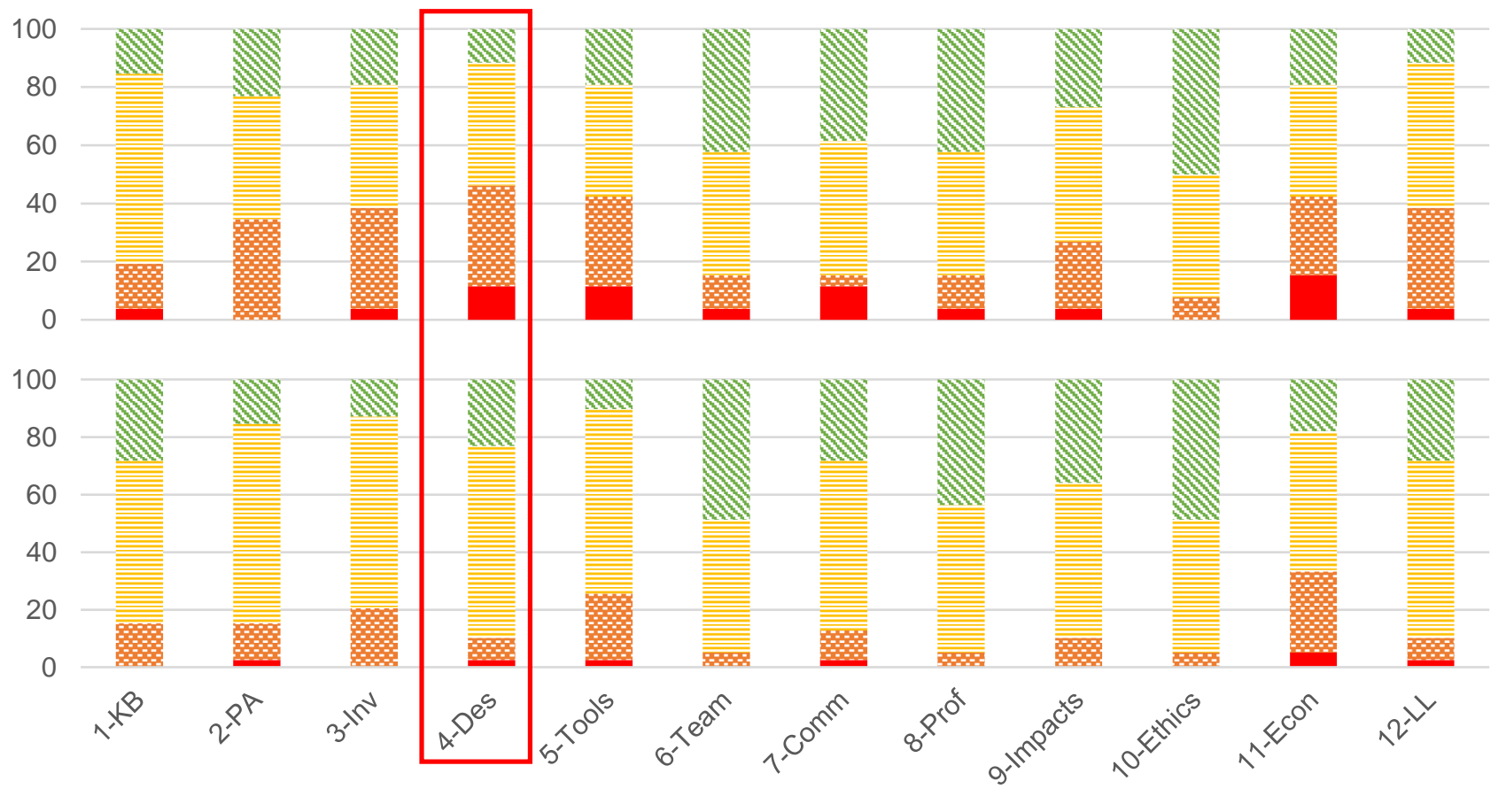

- Not Competent Marginally Competent $\quad$ Competent $\quad$ Highly Competent

Fig. 4. Year 2 student self-perception graduate attribute survey data from $2017 \mathrm{~W}$ (top, $\mathrm{n}=26 / 120$ ) and 2019W (bottom, $\mathrm{n}=$ $39 / 114)$. Data was not collected in 2018 W. Box indicates GA4 - Design. Results suggest an increase in the comfort level of students with design content.

\subsection{CHBE 221}

Student evaluations of the course were completed by 42 out of 105 students (40\%). Students rated a variety of items on a five-point Likert scale from strongly disagree to strongly agree. Results from questions related to the overall course can be seen in Table 2. Interestingly, the distribution of responses is quite similar that seen for CHBE 220.

Table 2: CHBE 221 Student course evaluation responses

\begin{tabular}{|l|c|c|c|c|c|}
\hline Question & SD & D & N & A & SA \\
\hline $\begin{array}{l}\text { The assigned workload for } \\
\text { the course was heavy }\end{array}$ & 2 & 12 & 20 & 7 & 1 \\
\hline $\begin{array}{l}\text { The course material is rather } \\
\text { advanced }\end{array}$ & 1 & 8 & 16 & 15 & 2 \\
\hline $\begin{array}{l}\text { The material is relevant for } \\
\text { my professional needs }\end{array}$ & 0 & 0 & 5 & 17 & 20 \\
\hline $\begin{array}{l}\text { The course material is } \\
\text { interesting }\end{array}$ & 0 & 0 & 4 & 15 & 23 \\
\hline
\end{tabular}

In terms of addressing the challenges anticipated at the beginning of the course, the approach taken provided a flexibility that allowed for different students to get what they wanted to out of the course. In terms of difficulty, several comments, presumably from the "bio" students, indicated that although the course only covered basic biological concepts, it was suitable for the audience and purpose, or that despite the limitations in scope of the course, the project allowed them to explore topics of interest in more detail. In terms of student buy-in, responses were positive but somewhat mixed. A few comments still opined that "not bio" students should not be obligated to take this course, but several other comments shared a common theme of

"I thought I hated bio, but this made me change my mind a bit, and I can see it being useful in the future".

Results in Table 2 suggest that overall, students saw the relevance of the material.

In terms of performance in the design-related deliverables, students did quite well. Several student teams really embraced the challenge that was presented to them and delivered comprehensive and sophisticated design proposals for complex processes, on a very wide range of topics. Beyond anecdotal data, students have indicated being more confident in their design skills, as further discussed in section 3.3.

In future iterations of the course, the basic structure and project-based design will again be employed. Beyond the regular calibration and rearranging of material common after a first offering of a course, it will likely be beneficial to include enrichment material for those students coming into the course with prior experience in biology.

\subsection{Graduate Attributes and Learning Outcomes}

One of the overarching goals of these curriculum changes was to improve students' comfort with the design 
process. One measure of the effectiveness of the approaches presented in this paper are student selfassessments of their confidence and skills in design. Students were surveyed on their self-assessed competence in each of the Engineers Canada Graduate Attributes (GAs). In 2017W and 2019W, this survey was sent to all CHBE students in term 2 lab courses at each year level. Students were presented with descriptors of each of the graduate attributes and asked to assess their competence on a four level Likert-scale. Data from year 2 students completing this survey is presented in Fig. 4. Data was not collected for $2018 \mathrm{~W}$ as the survey was not run. Significant improvements can be seen in a number of GAs such as GA 4 (Design), suggesting some benefit in at least student confidence in their design abilities. This is most likely attributable to CHBE 220/221 as no other significant curriculum changes impacting design content have occurred. Of course these are broad results and it is difficult to determine what may have caused this change and whether this is a lasting trend. A more systematic investigation of graduate attribute outcomes will be conducted in the future to further assess results of broad curriculum changes.

\section{CONCLUSION}

The development of two new second-year chemical and biological engineering courses integrating natural sciences with engineering science and design was successful in meeting a number of objectives outlined by stakeholders. Students appear to have greater perceived confidence in design in year 2 of the departmental programs. As the undergraduate program curricula in the department continue to evolve, further study of the effects of program changes will be undertaken to understand the impact of these changes on student graduate attributes, and identity as chemical and biological engineers.

\section{References}

[1] B. Frank, D. Strong, and R. Sellens, "The professional spine: Creation of a four-year engineering design and practice sequence," Proceedings of the Canadian Engineering Education Association, 2011.

[2] R. C. Bailie, J. A. Shaeiwitz, and W. B. Whiting, "An integrated design sequence: Sophomore and junior years," Chemical Engineering Education, vol. 28, pp. 52-52, 1994.

[3] K. Sheppard and B. Gallois, "The design spine: Revision of the engineering curriculum to include a design experience each semester," in American Society for Engineering Education Annual Conference Proceedings, 1999.

[4] F. L. Loepp, "Models of Curriculum Integration," The Journal of Technology Studies, vol. 25, no. 2, pp. 21-25, 1999.

[5] M. W. Carolina E., undefined Küpper-Tetzel, T. Weston, A. S. N. Kim, I. V. Kapler, and V. Foot-Seymour, "Enhancing the Quality of Student Learning Using Distributed Practice," in The Cambridge Handbook of Cognition and Education, J. Dunlosky and K. A. Rawson, Eds. Cambridge: Cambridge University Press, 2019, pp. 550-584.

[6] W. D. Seider, J. D. Seader, D. R. Lewin, and S. Widagdo, Product and Process Design Principles: Synthesis, Analysis and Evaluation., 4th ed. John Wiley \& Sons, 2017.

[7] R. C. Bailie, W. B. Whiting, J. A. Shaeiwitz, R. Turton, and D. Bhattacharyya, Analysis, Synthesis, and Design of Chemical Processes, Fifth Edition, 1st ed. Prentice Hall, 2018.

[8] J. Sibley, P. Ostafichuk, W. E. Roberson, B. Franchini, K. A. Kubitz, and L. K. Michaelsen, Getting started with teambased learning, First. Sterling, Virginia: Stylus, 2014. 